\title{
Questões linguísticas, educação indígena e interculturalidade: a experiência Waimiri- Atroari
}

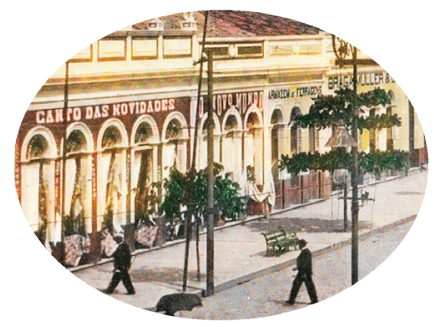

Ana Carla Bruno*

\section{Resumo}

Neste ensaio, eu apresento um breve resumo da situação lingüística do Estado do Amazonas e discuto o problema que comunidades, linguistas e pessoas envolvidas com projetos de Educação Indígenas enfrentam quando não trabalham a questão da "clarificação ideológica" dos mesmos. Usando minha própria experiência entre os Waimiri-Atroari, eu também discuto como o status dado a escola e a elaboração de ortografias estão relacionados a esta problemática.

Palavras-chaves: Problemas linguísticos; educação indígena; escola WaimiriAtroari, ortografia, estado do Amazonas.

\begin{abstract}
In this essay, I provide a brief overview about the Linguistic Diversity and research developed in the Amazonas State and I discuss the problems that communities, linguists, and people who are involved in Indigenous Education must deal when not given attention to the question of "Ideological Clarification". Using my own experience in the Waimiri-Atroari area, I also discuss how the status given to the schools and the elaboration of orthographies are related to this issue.
\end{abstract}

\footnotetext{
* Doutora em Antropologia e Linguística, Pesquisadora do Núcleo de Pesquisas em Ciências Humanas e Sociais do INPA. E-mail: abruno@inpa.gov.br
} 
Keywords: linguistic problems; indigenous education; Waimiri-Atroari schools, orthography, Amazonas state.

\section{Questões Linguísticas - A Situação do Estado do Amazonas}

Ao pensar-se sobre que papel a língua de um grupo tem na promoção e manutenção dos seus estilos de vida, pressupõe-se que o bem-estar e a sobrevivência física da espécie humana dependem não somente das condições biológicas, mas da existência de uma rede intelectual de vida, de um espaço que contemple a diversidade linguística (KRAUSS, 1996). Nesse sentido, a existência desta rede intelectual pode estar ameaçada quando a língua materna de um grupo de falantes não é necessariamente a língua oficial de um país. No Brasil, a língua portuguesa é considerada uma língua oficial e língua materna para a grande maioria de brasileiros. No entanto, esta não é a realidade para muitas etnias indígenas brasileiras que falam suas próprias línguas.

De acordo com Rodrigues (2001), atualmente no Brasil são reconhecidas perto de 160 línguas indígenas, sendo que sua grande maioria concentra-se na Amazônia Legal. Essas línguas estão agrupadas e distribuídas em dois troncos linguísticos, Macro-Jê e Tupi, e 13 famílias. Existem ainda línguas isoladas que não estão relacionadas com nenhum desses troncos ou famílias. Embora a questão da classificação não esteja totalmente esclarecida, pois existem línguas que ainda não foram incluídas nessa classificação, uma questão importante que necessita ser pesquisada é o número de falantes que existe para cada língua (ativo e passivo) e o grau de transmissão dessas línguas para as crianças. Moore (2000) através de um levantamento estatístico (que segundo ele está baseado em dados precários) constatou que no Brasil $24 \%$ das línguas são faladas por grupos com população de 50 pessoas ou menos; $8 \%$ por grupos de 51 -cem pessoas; $25 \%$ por grupos com $101-250$ pessoas; $18 \%$ por grupos na faixa de 251-500 falantes, $10 \%$ por grupos com população estimada entre 501 e mil falantes. Apenas 15\% do total de línguas indígenas brasileiras são faladas por grupos superiores a mil pessoas.

OAmazonas é o Estado que tem a menor concentração de pesquisas por linguistas brasileiros, enquanto tem, por longe, o maior número de línguas indígenas. Além da necessidade científica da pesquisa e documentação dessas 
línguas, há um grande interesse por parte das próprias comunidades indígenas em ter acesso a um centro de linguística. Muitas dessas comunidades solicitam a presença de linguistas profissionais para documentar aspectos da sua língua e sua cultura, apoiar projetos de revitalização e manutenção de línguas e cultura e assessorar projetos de educação indígena. O linguista que desejar realizar a documentação de alguma dessas línguas necessitará não apenas desenvolver um bom trabalho de documentação que compreenda conhecimento etnológico do grupo e a produção de uma descrição gramatical e um dicionário, mas atender especificidades da região.

O primeiro desafio que encontramos é não ter dados concretos de quantas línguas de fato são faladas ainda no Estado. Segundo a Fundação dos Povos Indígenas - FEPI - existem 66 etnias indígenas na região e, dessas 66 mais de 50 falam a língua. Várias línguas estão em situação precária com poucos falantes e não estão sendo transmitidas para as novas gerações. Nessa situação, podemos citar como exemplos, as línguas Dessana, Tariana, Apurinã, Munduruku, entre outras. Essa perspectiva é mais caótica quando pensamos que no Estado do Amazonas apenas quatro linguistas vinculadas às instituições de Ensino e Pesquisa (Frantomé Pachêco - UFAM, Walteir e Silvana Martins - UEA e Ana Carla Bruno - INPA) desenvolvem trabalhos na área de Linguística Indígena (imagine se pensarmos em linguistas indígenas). Claro que não pudemos esquecer e ressaltar as outras pesquisas linguísticas também desenvolvidas com línguas da região por pesquisadores que anteriormente foram professores da Ufam, entre eles, o Dr. Henri Ramirez (Tukano, Baniwa e Yanomami) e Dra. Dulce Franceschini (Saterê-Mawé), e pesquisadores no Inpa, o Dr. Odile Lescure (Tukano) e Dra.Françoise Grenand. Por outro lado, existem vários linguistas trabalhando no Amazonas, mas que não moram na região, por exemplo: Pattie Epps, Kristine Stenzel, Luke Flemming, Elsa Gomes, Alexandra Aikenvald (todos eles estudando línguas faladas no Alto Rio Negro). No entanto, é preciso formar pessoas da região para atuar em projetos de descrição e documentação dessas línguas, pois a demanda e número de línguas é um desafio. Destaca-se ainda o fato que no Estado temse um grande número de indígenas vivendo nas cidades (Manaus, São Gabriel da Cachoeira, Santa Isabel, Lábrea, Humaitá, Tefé, Benjamin Constant só para citar algumas). Grande parte desses indígenas trabalha na chamada economia 
informal ou subempregado em atividades temporárias: artesanato, pequenos comércio, venda de dindin, biscates, empresas de limpeza e de segurança. As mulheres em casas de família. No entanto, esses mesmos agentes sociais permanecem estabelecendo relações com suas aldeias.

Vivendo nas cidades muitos destes indígenas frequentam escolas tradicionais e na maioria das vezes a escola formal ignora a multicultural idade existente no Amazonas legitimando todo um preconceito e desconhecimento dessa diversidade. Ressalta-se ainda que muitas vezes na utilização de uma metodologia homogênea, os professores nem notam as dificuldades ou capacidades que os alunos indígenas possuem. A falta de compreensão do que venha ser uma educação de fato intercultural, nos fez refletir sobre outros aspectos: E quando esse mesmo indígena vivendo na cidade consegue "burlar essa teia e sistema excludente" chegando à universidade? Ao aceitarmos esses alunos indígenas num sistema de cotas diferenciadas, necessitaríamos ter também uma postura diferenciada no momento de avaliação. Se os alunos cursaram todas as disciplinas, fizeram todos os trabalhos, demonstraram que são capazes. Não é o fato de não escrever uma dissertação no Português padrão que seria motivo de prejudicá-los. Por outro lado, teríamos outro dilema: qual seria a banca de conclusão de graduação, mestrado ou doutorado que estaria apta para ler seus trabalhos em uma língua nativa? Estariam os alunos também aptos (tem a língua um sistema de escrita, materiais como gramática e dicionário) para escrever em suas línguas nativas? Diante dessa situação é importante refletir sobre alguns problemas relacionados a uma Educação Bilíngue e Intercultural.

\section{Interculturalidade e clarificação ideológica}

Enquanto em muitos países existe uma discussão e esforços específicos para oferecer acesso aos indígenas às universidades e instituições de pesquisa, no Brasil os indígenas não conseguem nem concluir os ensinos fundamental e médio. Embora o governo brasileiro reconheça os projetos educacionais das comunidades, o mesmo não compreende e não acomoda (respeita) as diferenças linguísticas, os diferentes estilos de vida desses grupos. Como resultado a escola termina modificando a organização sociocultural dos mesmos. De acordo com 
Januário (2002, p. 18), interculturalidade "é o diálogo entre e com as culturas... assim uma educação intercultural valoriza o desenvolvimento de estratégias que promovem a construção das identidades, sem que uma se sobreponha em relação à outra". No entanto, é possível observar que as atitudes, os desejos e as expectativas dos grupos que vivenciam experiências interculturais no nosso País não são claramente esclarecidas nos projetos educacionais.

As próprias comunidades necessitam refletir sobre o conteúdo dessa educação intercultural e suas diferentes formas, sobre a maneira que ela é ensinada e transmitida. "Quais aspectos da minha cultura quero presevar?” De que forma vamos interagir com a aquisição de novas formas de conhecimento oriundas de um contexto cultural diferente? Será que realmente queremos aprender através da escola aspectos da nossa língua e cultura?

As respostas para essas perguntas parecem simples, mas na realidade elas escondem medos, ansiedades e muitas vezes conflitos políticos. De moo geral em projetos de Educação bilíngues e interculturais, essa questão não é discutida. Esta falta de atenção e esclarecimento aos medos e ansiedades faz com que muitos programas de Educação interculturais não funcionem na sua plenitude, ou simplesmente tornem-se um problema para a comunidade. E quando se busca compreender porque não funcionaram, procura-se e tenta-se explicar as falhas através de aspectos técnicos do projeto, como por exemplo, os materiais educativos não eram apropriados, o currículo não refletia a realidade dos alunos, os professores realmente não estavam envolvidos. No entanto, Dauenhauer e Dauenhauer (1998) explicam que não percebemos que as causas para o não funcionamento do programa está realmente vinculado à falta de um "esclarecimento ideológico". E a principal pergunta e reflexão a ser feita é: Quais são realmente as expectativas da comunidade com esse programa de educação? Paralelo a essa pergunta, muitas vezes outros questionamentos são elaboradas: 1) "Por que eu preciso ser alfabetizado na minha língua se ela não tem valor?”; 2) "Nossa língua não nos ajudará ser respeitado pelos não indígenas, nem garantirá bons empregos"; 3) "Nossa língua não serve para nada, queremos aprender Português [...]"; 4) "Essas histórias mitológicas e canções são coisas dos velhos; 5) "Eu não quero que meus filhos aprendam a língua indígena, mas Português". Ressalta-se ainda que esta falta de clarificação ideológica não é vivenciada apenas pelas comunidades envolvidas, mas também pelos não indígenas que trabalham com essas comunidades em seus projetos. 
A concepção de escola que temos não acomoda os estilos, tempo e padrões de vida das comunidades: o tempo de fazer roçado, o tempo das preparações das festas e cerimônias (por exemplo, os Waimiri-Atroari passam semanas se preparando para suas festas), o tempo das caçadas e pescarias, o tempo para aprender fazer artesanato. De fato o que observamos é que para que as escolas indígenas sejam reconhecidas pelas secretarias de Educação é necessário que eles cumpram uma determinada carga horária, e na prática muitas vezes as atividades desenvolvidas não são consideradas como aulas. Ao final, instala-se certo sentimento de culpa entre participar das atividades tradicionais e organizar ou preparar as atividades da escola.

\subsection{A Experiência dos Waimiri-Atroari}

Os Waimiri-Atroari, grupo pertencente à família lingüística Karib estão dispersos numa região dos afluentes da margem esquerda do Baixo Rio Negro e do Rio Amazonas, entre os Estados do Amazonas e Roraima compreendendo as bacias dos rios Camanaú/Curiaú, Alalaú/Jauaperi, e uma parte da BR-174 (Manaus-Boa Vista). Com uma população de 1.113 Kinja (autodenominação do grupo), distribuídas em 19 aldeias, os Waimiri-Atroari vivem do produto de suas roças coletivas, da coleta de frutos silvestres, da caça e da pesca.

A língua, que leva o mesmo nome do grupo, é falada por crianças, adultos e velhos. Linguisticamente, quando comparado com outros grupos da Amazônia, a língua Waimiri-Atroari mostra-se numa excelente condição. Ao longo do território temos diferenças dialetais, notadamente mais expressivas entre as aldeias do norte e do sul da reserva, respectivamente situadas nos vales do rio Alalaú e Camanaú. Em diversas ocasiões (conversas e discussões sobre a língua) os Waimiri-Atroari explicitam e brincam com tais diferenças imitando o "modo de falar" dos seus parentes. Minha experiência entre os WaimiriAtroari pode ser dividida em dois períodos: a) o período que fui professora dos Kinja entre 1991-1993 e b) e o período que dei assessoria linguística para eles entre 1995-2000.

Entre 1988 e 1993, os Waimiri-Atroari no processo de escola formal, através do Subprograma de Educação do Programa Waimiri-Atroari (convênio FUNAI/Eletronorte), tinham professores não indígenas dando aulas para 
eles. A partir de 1994, devido a alta rotatividade desses professores já que os mesmos não aguentavam ficar mais de dois anos ensinando nas aldeias, os Waimiri-Atroari decidiram que eles mesmos seriam os professores das suas escolas.

Um fato interessante é que antes de tornarem-se professores, os Waimiri-Atroari associavam atividades como: ler, preparar aulas e estudar como atividades que não eram de fato "trabalho" dizendo: kaminja tamxa!, ou seja, "os não indígenas" são preguiçosos". Trabalho de verdade era caçar, pescar e fazer roçado. Deparando-se com o problema de dividir seu tempo entre "trabalho verdadeiro" versus "trabalho não verdadeiro", os professores sofriam grande pressão da comunidade e uma cobrança interna. Por um lado, a comunidade (as antigas lideranças) dizia que os professores se transformaram em tamxa preguiçosos como os não indígenas na medida em que ficavam estudando, lendo e preparando aulas, e que eles não estavam aprendendo como ser verdadeiros Kinja autodenominação dos Waimiri-Atroari, bons caçadores, pescadores, confeccionadores de artesanato por isso "não acreditavam no trabalho deles [...]".

Por outro lado, os professores Waimiri-Atroari se defendiam dizendo que "não era fácil dividir o tempo para aprender como se faz artesanato, caçar, aprender os cantos, preparar aulas e participar dos cursos de formação". Como resultado, um dos problemas observados no Programa de Educação Waimiri-Atroari foi que muitos professores indígenas ficavam desapontados e desencorajados quando seus parentes não reconheciam os seus trabalhos indo apenas para as aulas dos não indígenas que continuavam assessorando o projeto de educação.

\subsubsection{A Ortografia Waimiri-Atroari}

Sistemas ortográficos não devem ser elaborados simplesmente como uma redução da fala para escrita, mas como processo de escolha de símbolos que carregam significados históricos, culturais e políticos. Em minha experiência na área Waimiri-Atroari, foi observado que quando os Kinja vivenciaram as primeiras experiências nos processos de alfabetização, as ortografias utilizadas por eles tiveram diferentes significados históricos e políticos.

Até recentemente, os Waimiri-Atroari não tinham contato com a 
escrita. Em 1985, uma aldeia da área de estrada (aldeia Iawara) teve contato com um casal de missionário do Conselho Indigenista Missionário (CIMI) que através de estudos linguísticos estabeleceram uma proposta fonológica e desenvolveram um alfabeto. Eles ensinaram perto de 25 homens a ler e escrever. Algum tempo depois, a Fundação Nacional do Índio (FUNAI) proibiu a entrada do casal na área indígena, mas os indígenas gostaram da experiência e quiseram dar continuidade aos estudos (DO VALE, 2002). Em 1986, outro casal de missionários do Evangelical Mission of the Amazonian (MEVA) tentaram continuar o trabalho de alfabetização naquela aldeia. Eles também fizeram uma descrição preliminar da Fonologia e estabeleceram outra ortografia que divergia da ortografia do Cimi (ver Tabela 1). Posteriormente, esse casal também foi expulso pela Funai. Em 1987, o pesquisador do Museu Nacional, Márcio Silva, para realizar sua pesquisa sobre parentes coiniciou na região dos rios Camanaú/Curiaú, um processo educacional na língua materna, utilizando a mesma ortografia do casal do Cimi só que agora numa aldeia diferente (aldeia Cacau).

$\mathrm{Na}$ Tentativa de minimizar os impactos ambientais e socioculturais provocados pela construção da usina Hidroelétrica de Balbina, a Funai e Eletronorte conjuntamente com a comunidade implantaram um Projeto (iniciado em julho de 1987) visando desenvolver ações de assistência e apoio a esta comunidade através de programas de saúde; produção e meio ambiente; educação; documentação e memória e vigilância dos limites. Assim em 1988, os Waimiri-Atroari decidiram que qualquer experiência educacional deveria ser realizada em todas as aldeias. De 1988 a 1993, a Funai contratava professores não indígenas ${ }^{1}$ para ensinar os Waimiri-Atroari escrever e ler em sua língua, como também Português e Matemática. Durante esse tempo o Programa Waimiri-Atroari também contratou uma linguista da Universidade Federal do Rio de Janeiro, mas ela era bastante ocupada e prestava assessoria lingüística para vários outros grupos indígenas. Então trabalhávamos da seguinte forma: duas vezes ao ano nos reuníamos para falarmos sobre as dúvidas linguísticas. O problema é que em todas estas discussões os Waimiri-Atroari não estavam presentes devido ao contexto histórico-sociocultural que os mesmos se encontravam. Os professores kaminja (não indígenas) discutiam nas aldeias com os Kinja e levavam as dúvidas e problemas para as reuniões. Ao retornar às aldeias, os professores kaminja falavam sobre as reformulações ortográficas 
estabelecidas para os Kinja. No decorrer do processo educacional, um clima de insegurança foi se instaurando em relação a escrita da língua tanto entre os Kinja (mesmo os já alfabetizados) quanto também entre os professores kaminja. Indubitavelmente, a rotatividade de professores kaminja e a falta de uma assessoria linguística mais permanente, contribuíam também para instauração desse clima. Em 1994 os Waimiri-Atroari decidiram investir na formação de professores indígenas, visto que os professores não indígenas não aprendiam sua língua e não permaneciam muito tempo nas aldeias. Apesar de ter vivido entre os Waimiri-Atroari entre 1991 a 1993, minha "carreira como linguista" iniciou em 1994 e certamente eu só fui aceita por eles porque convivi anteriormente com os mesmos. Naquele momento eles estavam cansados de pesquisas linguísticas e antropológicas. Em 1995, nós (a comunidade, a coordenadora do Subprojeto de Educação e eu) decidimos que necessitávamos fazer algumas modificações na ortografia para tentar "unificá-la". Naquele período, indígenas de diferentes aldeias usavam diferentes ortografias. Às vezes grupos de indígenas de uma mesma aldeia utilizavam diferentes ortografias baseados nas experiências que foram expostos anteriormente.

Os professores Waimiri-Atroari queriam produzir materiais educacionais na língua para ajudá-los, mas estavam preocupados que esses materiais não levassem em consideração as diferenças dialetais ou não fossem bem utilizados tendo em vista as diferentes maneiras que a língua estava sendo escrita. Então, decidimos repensar a ortografia conjuntamente com os professores. Fomos a diversas aldeias e perguntamos à comunidade várias questões: a) o que é que eles pensavam sobre a ortografia utilizada na escola; b) o que deveria mudar ou permanecer do jeito que estava; c) das diferentes ortografias utilizadas no passado que aspectos deveríamos continuar usando. Mesmo não concordando linguisticamente com alguns símbolos utilizados anteriormente, eu não queria fazer mudanças profundas na ortografia, visto que muitos Kinja já estavam acostumados com alguns símbolos e escreviam bem.

Organizamos então um grande encontro na área indígena onde 35 Waimiri-Atroari foram selecionados pela comunidade para discutir aspectos da ortografia e estabelecer as mudanças necessárias como, por exemplo: marcar as vogais longas que não estavam sendo mais marcadas porque os professores não indígenas não conseguiam escutá-las, mas os Kinja percebiam que "algo estava faltando" quando escreviam certas palavras. Os não indígenas não escutavam 
as diferenças entre kymy [k,Ém,É] “bacaba” e kymyy [k,Ém,É,É,É mão. Nas Tabelas 1 e 2, apresentamos algumas diferenças entre as ortografias utilizadas pelos Waimiri-Atroari.

Tabela 1-Diferenças entre as ortografias anteriores e a utilizada atualmente nas escolas

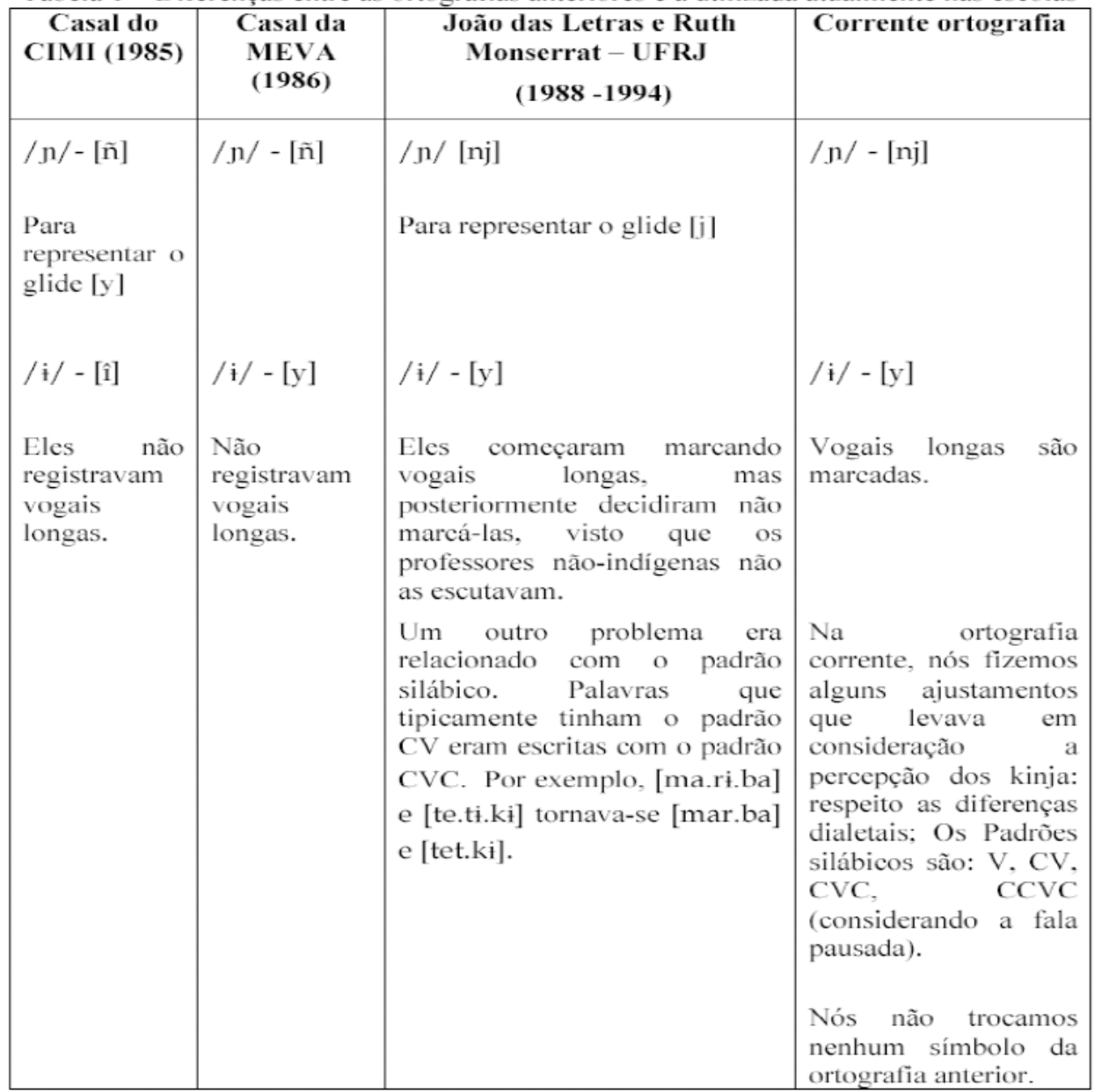


Tabela 2-Ortografia Corrente (Bruno 2003)

\begin{tabular}{|c|c|}
\hline Fonemas & Símbolos Ortográficos \\
\hline$/ \mathrm{p} /$ & $\mathrm{p}$ \\
\hline$/ \mathrm{t} /$ & $\mathrm{t}$ \\
\hline$/ \mathrm{t} \int /$ & $\mathrm{tx}$ \\
\hline$/ \mathrm{k} /$ & $\mathrm{k}$ \\
\hline$/ b /$ & b \\
\hline$/ \mathrm{d} /$ & $\mathrm{d}$ \\
\hline$/ d_{3} /$ & dj \\
\hline$/ \mathrm{m} /$ & $\mathrm{m}$ \\
\hline$/ \mathrm{n} /$ & $\mathrm{n}$ \\
\hline$/ \mathrm{n} /$ & nj \\
\hline$/ \mathrm{s} /$ & s \\
\hline$/ \int /$ & $x$ \\
\hline$/ \mathrm{h} /$ & h \\
\hline$/ \mathrm{r} /$ & $\mathbf{r}$ \\
\hline$/ w /$ & w \\
\hline /i/ & i (também para representar o glide) \\
\hline$/ \mathrm{e} /$ & $\mathrm{e}$ \\
\hline$/ \mathrm{i} /$ & $\mathrm{y}$ \\
\hline$/ \mathrm{a} /$ & a \\
\hline$/ \mathrm{u} /$ & $\mathrm{u}$ \\
\hline /o/ & o \\
\hline Vogais longas são marcadas como VV & aa, yy, ee, oo \\
\hline
\end{tabular}

Interessantemente, a reação do coordenador da Funai/Eletronorte pegou-me de surpresa. Ele manifestou certa indignação porque realizamos o encontro para fazer os "ajustes" na ortografia sem a sua presença. Devido sua reserva em relação a projetos de pesquisas, ele questionou-me se eu tinha alguma associação com missionários americanos, visto que continuei usando o símbolo ' $y^{\prime 3} 3$ para representar o fonema /„É /. Ele também não quis que 
o livro de alfabetização, que a comunidade e eu tínhamos elaborados, fosse publicado pela Norwegian Rainforest Foundation (agência que financiava minhas pesquisas de campo naquele momento) que já tinha o recurso e previa a edição colorida de todos os desenhos elaborados pelos professores. Tomando a decisão que outra instituição deveria publicá-lo. O programa Waimiri-Atroari conseguiu por meio da editora da Universidade Federal do Amazonas (UFAM) a publicação do livro de alfabetização em preto e branco, no entanto, esperamos um ano para que o material ficasse pronto. Quando finalmente o livro chegou nas aldeias, ele não foi utilizado como esperávamos devido todos esses conflitos e problemas associados ao mesmo.

Embora eu tenha tido muitos problemas, acredito que qualquer ortografia deve representar os sons da língua em questão, não somente sendo fonologicamente bem elaborada, mas também levando em consideração as crenças e perspectivas dos falantes. Uma ideia do que acontece na língua e como os sons podem ser representados devem ser fornecidos pelos linguistas à comunidade interessada, explicando as consequências das escolhas, mas só os falantes devem decidir. A ideia que os indígenas não são capazes de compreender o que é, e como funciona a linguística deve ser desencorajada. Eu lembro que ao ensinar Fonologia para os Kinja, os mesmos realmente gostavam e refletiam sobre os sons de sua língua. Questionando-me várias vezes porque antes (quando os não indígenas eram professores) eles não participavam dos encontros educacionais se eles eram os falantes da língua discutida nas reuniões.

Finalmente, necessitamos refletir mais aprofundadamente sobre as ideias de Schieffelin e Doucet (1992, p. 441), quando elas argumentam que "qualquer política linguística que use puramente 'fatos linguísticos', correrá o risco de percorrer o caminho errado visto que a língua não é só um instrumento de comunicação; ela carrega valores simbólicos que condiciona as esferas sociais, políticas e econômicas [da vida]”. Por isso, a questão da clarificação ideológica deve ser considerada antes de iniciarmos qualquer projeto de Educação Indígena. A experiência descrita neste ensaio demonstra que nossa concepção de escola e nossa limitação para respeitar as diferenças e o outro terminam sendo um instrumento criador de conflitos, limitando assim o diálogo intercultural. 


\section{Notas}

${ }^{1}$ Meu primeiro contato com os Waimiri-Atroari aconteceu em 1991. Naquele tranquei a universidade e fui trabalhar como professora na área indígena Waimiri-Atroari mais especificamente na Aldeia Alalaú onde fui professora por dois anos.

${ }^{2} \mathrm{Na}$ verdade, se eu pudesse ter escolhido eu usaria o símbolo ' $\mathrm{y}$ ' para representar o glide $/ \mathrm{j} /$. Mas a comunidade preferiu continuar usando o símbolo para representar o fonema /„É/ como estabelecida na ortografia do casal do MEVA.

\section{Referências}

BRUNO, Ana Carla. Proposta ortográfica para língua Waimiri-Atroari. Manaus: PWA. In: Waimiri-Atroari Grammar: Some Phonological, Morphological, and Syntatic Aspects. PhD Dissertation. Tucson: University of Arizona, 1995.

DAUENHAUER, Nora Marks and DAUENHAUER, Richard. Technical, emotional, and Ideological issues in reversing language shift: examples from Southeast Alaska. In: Endangered Languages: current Issues and future prospects, ed. Lenore A. Grenoble and Lindsay J. Whaley, 1998, pp. 57-98. Cambridge: Cambridge University Press.

DO VALE, Maria Carmen Rezende. Waimiri-Atroari em festa: é maryba na floresta. Manaus: UA/ICHL, 2002 (Dissertação de Mestrado).

JANUÁRIO, Elias. Ensino Superior para Índios: Um Novo Paradigma na Educação. In: Cadernos de Educação Escolar Indígena. n. 1, v. 1. Barra de Bugres: Unemat, 2002.

KRAUSS, M. Linguistic and Biology: Threatened Linguistic and Biology Diversity Compare. In: CLS32 Papers from the Parassession on Theory and Data in Linguistics. Chicago: Chicago Linguistic Society, 1996, p. 69-75.

MOORE, Denny. The Languages of Lowland South America. In: Comunicação no colóquio Language Endangerment, Research, and Documentation. Setting Priorities for the 21st, 12-17 February 2000, Bad Godesberg, Alemanha, 2000.

RODRIGUES, Aryon Dall'gna. Línguas, 2001. Informação disponível no site do Instituto socioambiental (ISA) www.socioambiental.org/website/povind/ linguas/index.html 
SCHIEFFELIN, Bambi e DOUCET, Rachelle Charlier. “The 'real' Haitian Creole: Meta-linguistics and orthographic choice” In: Pragmatics. vol. 2 e 3, 1992, p. 427-444. 